PRODUÇÃO ANIMAL

\title{
COMPORTAMENTO INGESTIVO DE VACAS F1 HOLANDÊS X ZEBU ALIMENTADAS COM DIFERENTES FONTES DE COMPOSTOS NITROGENADOS
}

\section{INGESTIVE BEHAVIOR OF F1 HOLSTEIN X ZEBU COWS FED DIETS CONTAINING DIFFERENT SOURCES OF NITROGEN COMPOUNDS}

\author{
Silvio Humberto Cardoso de Almeida Filho ${ }^{1 *}$ \\ Vicente Ribeiro Rocha Júnior ${ }^{2}$ \\ Gustavo Chamon de Castro Menezes² \\ José Reinaldo Mendes Ruas² \\ Ana Cássia Rodrigues de Aguiar ${ }^{2}$ \\ Pedro Felipe Santana ${ }^{2}$ \\ Lucas Daniel Alcântara Borges ${ }^{2}$ \\ Natanael Mendes Costa ${ }^{2}$ \\ 1 Universidade Estadual do Sudoeste da Bahia, Itapetinga, BA, Brasil. \\ 2 Universidade Estadual de Montes Claros, Janaúba, MG, Brasil. \\ *Autor para correspondência - vicente.rocha@unimontes.br
}

\section{Resumo:}

Avaliou-se o comportamento ingestivo de vacas F1 Holandês x Zebu com $80 \pm 12$ dias de lactação e produção média de $20 \pm 0,42 \mathrm{~kg}$ de leite/dia, alimentadas com diferentes fontes de compostos nitrogenados: farelos de soja, de girassol, de mamona desintoxicados e ureia. Utilizaram-se dois quadrados latinos $4 \times 4$, compostos de quatro animais e quatro dietas, com quatro períodos experimentais. O comportamento ingestivo foi obtido por avaliação visual para definir o tempo despendido em alimentação, ruminação, ócio e para avaliar mastigações merícicas e tempo de mastigação por bolo ruminal. Não houve diferença no tempo em alimentação $(P=0,1384)$, ruminação $(P=0,5964)$, ócio $(\mathrm{P}=0,6314)$, número de períodos de alimentação $(\mathrm{P}=0,5995)$, de ruminação $(\mathrm{P}=0,4575)$ e de ócio $(\mathrm{P}=0,4151)$, duração dos períodos de alimentação $(\mathrm{P}=0,2711)$, ruminação $(\mathrm{P}=0,8699)$ e ócio $(\mathrm{P}=0,4025)$, em função da dieta utilizada. Não houve diferença na produção de leite $(\mathrm{P}=0.2755)$ das vacas entre as dietas experimentais. A adição do farelo de girassol à dieta, em relação à utilização de ureia, resulta em menor consumo de FDN em minutos $/ \mathrm{kg}(\mathrm{P}=0,0399)$ e consequentemente menor eficiência de alimentação da matéria seca $(\mathrm{P}=0,0069)$, comparado ao tratamento com ureia. Assim, algumas características do comportamento ingestivo de vacas F1 Holandês x Zebu em lactação podem ser alteradas pelo uso de diferentes fontes nitrogenadas; entretanto, sem prejudicar a produção média de $20 \mathrm{~kg}$ de leite corrigida para $3,5 \%$ de gordura/dia.

Palavras-chaves: alimentação; fibra; fontes protéicas; produção de leite; ruminação

\begin{abstract}
:
We evaluated the feeding behavior of F1 Holstein $\mathrm{x}$ Zebu lactating cows at $80 \pm 12$ days of lactation and average production of $20 \pm 0.42 \mathrm{~kg}$ of milk / day, fed different sources of nitrogen compounds: soybean meal, sunflower meal, detoxified castor meal, and urea. We used two 4 x 4 Latin squares, consisting of four animals, four diets, and four experimental periods. The feeding behavior was obtained by visual evaluation to set the time spent eating, ruminating, idling and to assess ruminating chews and chewing time for ruminal boluses. There was no difference regarding the times spent in feeding $(\mathrm{P}=0.1384)$, rumination $(0.5964)$, idleness $(\mathrm{P}=0.6314)$, number of periods in feeding $(\mathrm{P}$
\end{abstract}


$=0.5995)$, rumination $(\mathrm{P}=0.4575)$, and idleness $(\mathrm{P}=0.4251)$, duration of periods in feeding $(\mathrm{P}=0.2711)$, rumination $(\mathrm{P}=0.8699)$ and idling $(\mathrm{P}=0.4025)$, depending on the used diet. There was no difference in milk production $(\mathrm{P}=0.2755)$ of the cows among the experimental diets. The addition of sunflower meal to the diet, regarding the use of urea, results in lower consumption of NDF in minutes $/ \mathrm{kg}$ $(\mathrm{P}=0.0399)$ and, thus, a lesser feed efficiency of dry matter $(\mathrm{P}=0.0069)$. Therefore, some feeding behavior characteristics of F1 Holstein $\mathrm{x}$ Zebu lactating cows can be changed by using different nitrogen sources; however, without harming the average production of $20 \mathrm{~kg}$ of milk corrected to $3.5 \%$ fat / day.

Keywords: feeding; fiber; milk yield; protein sources; rumination.

Enviado em: 09 junho de 2015

Aceito em: 02 fevereiro de 2016

\section{Introdução}

Especialistas apontam a presente década como a da biomassa/bioenergia, criando-se um novo modelo de agricultura, não alimentar, responsável pela produção de matérias-primas energéticas renováveis, com potencial para substituir gradativamente o uso do petróleo ${ }^{(1)}$. No âmbito da produção de oleaginosas, a utilização dos grãos como fonte de lipídeos (ácidos graxos) para a produção do biodiesel tem apresentado um aumento significativo. Todavia, as transformações relacionadas à produção dessa fonte agroenergética são responsáveis pela geração de resíduos ou coprodutos. As tortas e os farelos são os principais coprodutos resultantes do processamento de grãos de oleaginosas pela indústria do biodiesel ${ }^{(2)}$ com potencial econômico para uso em dietas de ruminantes ${ }^{(3,4)}$.

Além da utilização dos coprodutos do biodiesel, o uso de nitrogênio não protéico (NNP), como a ureia, como fonte de nitrogênio degradável no rúmen, em substituição parcial ao farelo de soja, é uma estratégia nutricional bastante comum no Brasil e visa à redução dos custos com alimentação, sem alteração da produção de leite. A substituição total da fonte de proteína verdadeira convencional, o farelo de soja, pela ureia ${ }^{(5)}$ ou por outras fontes alternativas de compostos nitrogenadas, como os farelos/tortas de girassol ${ }^{(6)}$ e mamona ${ }^{(4)}$, na dieta de vacas mestiças em lactação pode ser uma importante estratégia para sistemas de produção de leite com este tipo de animal. Deve-se atentar, entretanto, para as diferenças nas degradabilidades ruminais dessas fontes nitrogenadas, o que pode influenciar no consumo e em suas características comportamentais.

A probabilidade de o alimento ser ingerido pelo animal depende da ação de fatores que interagem em diferentes situações de alimentação, comportamento animal e meio ambiente ${ }^{(7)}$.

O comportamento animal tem sido estudado e analisado por meio de atividades ingestivas com a finalidade de se verificar as causas para diferentes frequências de alimentação, ruminação, ócio e outras atividades, relacionadas, às vezes, com o tipo de dieta e que afeta negativa ou positivamente o consumo voluntário dos animais e, consequentemente, suas características produtivas. Tendo em vista que o uso de distintas fontes de compostos nitrogenados pode influenciar o processo digestivo no rúmen e, assim, o consumo pelo animal, considerando-se as possíveis diferenças na degradabilidade ruminal dessas fontes, objetivou-se por meio deste trabalho avaliar as características do comportamento ingestivo de vacas F1 Holandês x Zebu, em lactação, submetidas a dietas com diferentes coprodutos do biodiesel e ureia.

\section{Material e Métodos}

O experimento foi conduzido na Fazenda Experimental da Universidade Estadual de Montes Claros, em Janaúba/MG/Brasil, situando a $15^{\circ}$ 47' Sul e 43 18' Oeste, com 516 m de altitude. O clima do local é caracterizado por verão chuvoso e inverno ausente de chuva, tendo pluviosidade anual de 876 $\mathrm{mm}$, compreendido nos meses de novembro a março. Este trabalho foi aprovado pela Comissão de 
Ética em Experimentação e Bem Estar Animal da Universidade Estadual de Montes Claros, sob o número de Protocolo 053/2013.

A produção de leite e o consumo foram mensurados utilizando-se oito vacas F1 Holandês x Zebu com aproximadamente $80 \pm 12$ dias de lactação ao início do experimento. O delineamento experimental adotado foram dois quadrados latinos $4 \times 4$, simultâneos, compostos de quatro animais, quatro tratamentos e quatro períodos experimentais. As dietas experimentais foram compostas por fontes de compostos nitrogenados (farelos de soja, girassol, mamona desintoxicados e ureia) e silagem de sorgo como volumoso, sendo ofertadas na forma de dieta completa. $\mathrm{O}$ experimento teve duração de 72 dias, com períodos experimentais de 18 dias, sendo os 14 dias iniciais de adaptação dos animais às dietas e os quatro últimos dias de cada período para coleta de dados.

As vacas foram manejadas em baias individuais, alimentadas e ordenhadas duas vezes ao dia. As dietas foram formuladas de acordo com o National Research Counsil (NRC) ${ }^{(8)}$ para vacas de 500 $\pm 5 \mathrm{~kg}$ de peso corporal e produção média de $20 \pm 0,42 \mathrm{~kg}$ de leite com 3,5\% de gordura. A dieta foi fornecida na forma de ração total contendo $70 \%$ de volumoso (silagem de sorgo) e $30 \%$ de concentrado, caracterizados nas Tabelas 1 e 2. Foi realizada a desintoxicação do farelo de mamona segundo recomendação de Anandan et al ${ }^{(9)}$. Assim, o farelo de mamona foi misturado com solução de hidróxido de cálcio em uma proporção de $3 \mathrm{~g} / \mathrm{ml}$ de água e a concentração de hidróxido de cálcio foi de $40 \mathrm{~g} / \mathrm{kg}$ de farelo de mamona. Após mistura, o material tratado foi espalhado em uma superfície de concreto e deixado durante a noite e durante o dia exposto ao sol para secagem e posterior armazenamento em sacos. Os farelos de girassol e de soja e a ureia foram utilizados na forma como foram adquiridos.

Cada vaca foi submetida à observação visual para avaliação do comportamento ingestivo em dois dias consecutivos de cada período experimental após adaptação à dieta. No primeiro dia, foi feita a observação visual de cada animal a cada cinco minutos, durante 24 horas, para determinação dos tempos despendidos com alimentação (TA), ruminação (TR) e ócio (TO) e dos números de períodos de alimentação (NPA), ruminação (NPR) e ócio (NPO). Nestas avaliações, foi considerado como período a sequência de observações consecutivas para uma dada atividade (alimentação, ruminação ou ócio). No dia seguinte, foram realizadas as contagens do número de mastigações merícicas/bolo ruminal e a determinação do tempo despendido na ruminação de cada bolo ruminal, para cada animal, com a utilização de um cronômetro digital (Instrutemp/ITCD400, São Paulo/Brasil). Os valores do tempo despendido e do número de mastigações merícicas por bolo ruminal foram obtidos a partir das observações feitas durante a ruminação de três bolos ruminais, em três períodos diferentes do dia (10:00 às 12:00; 13:00 às 15:00 e 18:00 às 20:00), de acordo com metodologia descrita por Bürger et al. ${ }^{(10)}$. Algumas variáveis com comportamento ingestivo foram calculadas pelas seguintes fórmulas:

Duração do período de alimentação (DPA) = Tempo de alimentação / Número de refeições por dia;

Duração do período de ruminação $(\mathrm{DPR})$ = Tempo de ruminação / Número de períodos de ruminação por dia;

Duração do período de ócio (DPO) = Tempo de ócio (TO) / Número de períodos de ócio por dia;

Tempo de consumo por kg de matéria seca $(\mathrm{TCMS})=$ Tempo de alimentação / CMS;

Tempo de consumo por kg de fibra em detergente neutro (TCFDN) = Tempo de alimentação / CFDN;

Eficiência da ruminação da matéria seca $(\mathrm{RMS})$ = Tempo de ruminação / CMS;

Eficiência da ruminação da fibra em detergente neutro (RFDN) = Tempo de ruminação / CFDN;

Eficiência de mastigação da matéria seca $(\mathrm{MMS})$ = Tempo de mastigação total (TMT) / CMS;

Eficiência de mastigação da fibra em detergente neutro (MFDN) = TMT / CFDN.

A eficiência de alimentação (EA), a eficiência de ruminação (ER), o número de bolos ruminais por dia (NBR), o número de mastigações merícicas por dia (NM/dia) e o TMT foram obtidos segundo técnica descrita por Burger et al. ${ }^{(10)}$, sendo que o TMT foi calculado pela soma do tempo de alimentação com o tempo de ruminação. 
O consumo foi medido diariamente por diferença da oferta da dieta com $5 \%$ de sobras em relação à matéria seca fornecida. Foram coletadas amostra de alimentos e sobras em cada período experimental e secas em estufa de ventilação forçada à $55^{\circ} \mathrm{C}$ por 72 horas.

Tabela 1. Proporção dos ingredientes das dietas experimentais, composição química das dietas e dos ingredientes, na base da matéria seca (\%)

\begin{tabular}{|c|c|c|c|c|c|c|}
\hline \multirow{3}{*}{ Ingredientes } & & \multicolumn{5}{|c|}{ Dietas Experimentais } \\
\hline & & \multicolumn{4}{|c|}{ Farelos } & \multirow[b]{2}{*}{ Ureia } \\
\hline & & Soja & Girassol & \multicolumn{2}{|c|}{$\begin{array}{c}\text { Mamona } \\
\text { Desintoxicado }\end{array}$} & \\
\hline Silagem de sorgo & & 70,0 & 70,0 & \multicolumn{2}{|c|}{70,0} & 70,0 \\
\hline Farelo de soja & & 11,9 & 0,00 & \multicolumn{2}{|c|}{0,00} & 0,00 \\
\hline Farelo de Girassol & & 0,00 & 13,1 & \multicolumn{2}{|c|}{0,00} & 0,00 \\
\hline Farelo de Mamona & & 0,00 & 0,00 & \multicolumn{2}{|c|}{12,2} & 0,00 \\
\hline Milho moido & & 17,9 & 15,8 & \multicolumn{2}{|c|}{17,6} & 27,2 \\
\hline Ureia: sulfato de amônio ( $9: 1)$ & & 0,00 & 0,00 & \multicolumn{2}{|c|}{0,00} & 1,88 \\
\hline \multicolumn{2}{|l|}{ Suplemento mineral } & 0,92 & 0,92 & & 2 & 0,92 \\
\hline & & \multicolumn{5}{|c|}{ Composição química } \\
\hline Matéria Seca & & 42,2 & 42,5 & \multicolumn{2}{|c|}{42,19} & 42,20 \\
\hline Proteina Bruta & & 12,84 & 12,39 & \multicolumn{2}{|c|}{12,35} & 13,0 \\
\hline $\mathrm{NIDN}^{-1}$ & & 0,44 & 0,42 & \multicolumn{2}{|c|}{0,43} & 0,41 \\
\hline $\mathrm{NIDA}^{2}$ & & 0,02 & 0,02 & \multicolumn{2}{|c|}{0,02} & 0,02 \\
\hline Extrato Etéreo & & 1,15 & 2,33 & \multicolumn{2}{|c|}{1,73} & 1,27 \\
\hline Carboidratos Totais & & 75,0 & 72,6 & \multicolumn{2}{|c|}{76,3} & 76,4 \\
\hline Carboidratos não fibrosos & & 30,5 & 27,3 & \multicolumn{2}{|c|}{31,8} & 32,8 \\
\hline Fibra em detergente neutro & & 44,5 & 45,3 & \multicolumn{2}{|c|}{44,6} & 43,6 \\
\hline FDNcp & & 44,1 & 45,3 & \multicolumn{2}{|c|}{42,3} & 40,2 \\
\hline Fibra em detergente ácido & & 20,6 & 21,4 & \multicolumn{2}{|c|}{26,4} & 23,1 \\
\hline Lignina & & 3,02 & 3,65 & \multicolumn{2}{|c|}{3,14} & 3,24 \\
\hline Nutrientes Digestiveis Totais & & 65,3 & 65,4 & \multicolumn{2}{|c|}{65,0} & 65,1 \\
\hline \multicolumn{7}{|c|}{ Composição química dos ingredientes das dietas experimentais } \\
\hline Ingredientes (\%MS) & MS & PB & FDN & FDA & $\mathrm{EE}$ & Lignina \\
\hline Silagem de sorgo & 22,1 & 9,00 & 48,7 & 22,0 & 1,45 & 3,57 \\
\hline Milho grão moído & 87,9 & 7,27 & 11,9 & 2,95 & 2,48 & 1,35 \\
\hline Farelo de soja & 92,4 & 44,0 & 27,2 & 11,9 & 2,17 & 2,45 \\
\hline Farelo de girassol & 91,9 & 37,7 & 38,6 & 27,9 & 1,97 & 3,65 \\
\hline Farelo de mamona Detoxificado & 90,4 & 39,1 & 42,9 & 18,6 & 1,87 & 3,24 \\
\hline
\end{tabular}

As análises de matéria seca, proteína bruta, extrato etéreo, matéria mineral, nitrogênio insolúvel em detergente neutro (NIDN), nitrogênio insolúvel em detergente ácido (NIDA), fibra em detergente neutro corrigida para cinzas e proteínas e lignina foram determinados conforme Detmann et al. ${ }^{(11)}$. A fibra em detergente neutro e a fibra em detergente ácido, com as devidas correções para a presença de amido, foram determinadas de acordo com Van Soest et al. ${ }^{(12)}$ Os carboidratos não fibrosos (CNF) foram calculados de acordo com a equação descrita por Detmann e Valadares Filho ${ }^{(13)}$ : CNF=100 ( $\% \mathrm{~PB}+\% \mathrm{FDN}+\% \mathrm{EE}+\%$ cinzas). Para dietas com ureia, o CNF foi calculado pela equação proposta por Detmann et al. ${ }^{(11)}: \mathrm{CNF}=100-[(\mathrm{PB}-\mathrm{PBu}+\mathrm{U})+\mathrm{EE}+\mathrm{MM}+\mathrm{FDNcp}]$; sendo MM a matéria mineral e $\mathrm{PBu}$ o teor de proteína bruta proveniente da ureia $(\mathrm{U})$. Os nutrientes digestíveis totais (NDT) foram estimados de acordo com o $\mathrm{NRC}^{(8)}$. 
A produção de leite foi mensurada individualmente com uso de sistema automático de fluxo de leite da ordenhadeira e corrigidas para $3,5 \%$ de gordura $^{(14)}$.

Os dados obtidos foram submetidos à análise de variância do programa SISVAR ${ }^{(15)}$, segundo o modelo estatístico a seguir:

Em que:

$$
\mathrm{Y}_{\mathrm{k}(\mathrm{ij})}=\mu \mathrm{P}_{\mathrm{i}}+\mathrm{A}_{\mathrm{j}}+\mathrm{T}_{\mathrm{k}(\mathrm{ij})}+\mathrm{e} \mathrm{k}_{(\mathrm{ij})}
$$

$\mathrm{Y}_{\mathrm{k}(\mathrm{ij})}=$ Observação referente ao tratamento "k", dentro do período "i”" e animal “j”;

$\mu=$ Constante associada a todas as observações;

$\mathrm{P}_{\mathrm{i}}=$ Efeito do período " $\mathrm{i}$ ', com $\mathrm{i}=1,2,3$ e 4;

$A_{j}=$ Efeito do animal “ $j$ ”, com $j=1,2,3$ e 4;

$\mathrm{T}_{\mathrm{k}(\mathrm{ij})}=$ Efeito do tratamento " $\mathrm{k}$ ", com $\mathrm{k}=1,2,3$ e 4;

$\mathrm{e}_{\mathrm{k}(\mathrm{ij})}=$ Erro experimental associado a todas as observações ( $\mathrm{Yk}(\mathrm{ij})$ ), independente, que por hipótese tem distribuição normal com média zero e variância $\sigma^{2}$.

Quando significativas, as médias dos tratamentos foram comparadas pelo teste de Tukey ao nível de $5 \%$ de probabilidade.

\section{Resultados e Discussão}

Não houve influência das fontes nitrogenadas utilizadas nos tempos de alimentação $(P=0,1384)$, ruminação $(\mathrm{P}=0,5964)$ e ócio $(\mathrm{P}=0,6314)$ em horas por dia, tampouco nos períodos de alimentação e no tempo gasto com mastigação total e por bolo ruminal, como demonstrado na Tabela 2. A deficiência proteica pode limitar a produção animal devido ao baixo consumo de matéria seca. Esta deficiência é normalmente caracterizada pela baixa disponibilidade de nitrogênio amoniacal ruminal (NAR), o que restringe o crescimento microbiano e, por consequência, a utilização dos carboidratos fibrosos da forragem $^{(16)}$. Em estudos recentes visando à otimização do consumo de forragens tropicais, Detmann et al. ${ }^{(16)}$ observaram que a concentração mínima de $15 \mathrm{mg}$ de nitrogênio amoniacal ruminal (NAR) no fluido ruminal garante aos microrganismos disponibilidade de compostos nitrogenados para a síntese dos sistemas enzimáticos responsáveis pela degradação dos carboidratos fibrosos da forragem. Devido ao fato de as fontes nitrogenadas serem de características distintas, era de esperar que o fornecimento dos suplementos promovesse modificações no comportamento ingestivo, justificado por uma possível melhora na digestibilidade e taxa de passagem dos alimentos. No entanto, a falta de efeito ingestivo entre as fontes nitrogenadas firma-se sobre a capacidade de adaptação do animal, como demonstrado por Farmer et al. ${ }^{(17)}$, com a observação de pico de produção de amônia ruminal duas horas após a alimentação e retorno a níveis normais seis horas após.

A literatura nacional possui um consenso sobre os pontos avaliados neste experimento. $\mathrm{O}$ uso do nitrogênio não protéico em dietas contendo palma ${ }^{(18)}$, cana de açúcar ${ }^{(19)}$, torta de girassol ${ }^{(6)}$ e bagaço de mandioca ${ }^{(20)}$ não foi capaz de promover alteração no tempo de alimentação e ócio e no consumo de MS, mesmo em diferentes níveis de FDN.

O teor de extrato etéreo mais elevado na dieta com farelo de girassol (Tabela 1) poderia refletir em um possível efeito sobre o comportamento ingestivo dos animais. Entretanto, mesmo apresentando valor mais alto $(2,33 \%)$ em relação às demais dietas, esse teor de extrato etéreo é bem inferior ao limite máximo de $7 \%$ preconizado para dietas de ruminantes ${ }^{(21)}$. A maior concentração de extrato etéreo e menor de carboidratos não fibrosos poderia limitar a ingestão pelo retardamento da digestão ruminal da fibra devido à restrição ao crescimento microbiano ${ }^{(22)}$. Consequência final é que as exigências de proteína metabolizável dos ruminantes poderiam não ser atendidas pela proteína sintetizada pelos microrganismos, pois se entende que a disponibilidade de amônia, aminoácidos e peptídeos ruminais 
assim como o tipo de carboidrato podem aumentar a taxa e a quantidade de síntese microbiana ${ }^{(16)}$. Entretanto, como pode ser verificado na Tabela 1, o teor de energia (NDT) era semelhante entre as dietas experimentais e certamente a disponibilidade de energia proveniente das mesmas foi similarmente suficiente para atender ao crescimento microbiano em relação ao nível de produção de leite observado.

Tabela 2. Média das atividades inerentes ao comportamento ingestivo de vacas $F 1$ Holandês $\mathrm{x}$ Zebu alimentadas com diferentes fontes de compostos nitrogenados

\begin{tabular}{|c|c|c|c|c|c|c|}
\hline \multirow[t]{3}{*}{ Itens } & \multicolumn{6}{|c|}{ Tratamentos } \\
\hline & \multicolumn{3}{|c|}{ Farelos } & \multirow[b]{2}{*}{ Ureia } & \multirow[b]{2}{*}{ EPM } & \multirow[b]{2}{*}{ Pr $>$ Fc } \\
\hline & Soja & Girassol & $\begin{array}{c}\text { Mamona } \\
\text { Desintoxicado }\end{array}$ & & & \\
\hline Tempo de Alimentação (h./dia) & 6,44 & 6,33 & 6,33 & 5,50 & 0,31 & 0,1384 \\
\hline Tempo de Ruminação (h./dia) & 9,15 & 8,77 & 8,59 & 8,83 & 0,29 & 0,5964 \\
\hline Tempo de Ócio (h./dia) & 8,41 & 8,90 & 9,08 & 9,67 & 0,42 & 0,6314 \\
\hline Número de Períodos de Alimentação ( $\mathrm{n}^{\circ} /$ dia) & 16,1 & 16,7 & 16,5 & 15,1 & 0,92 & 0,5995 \\
\hline Número de Períodos de Ruminação ( $\mathrm{n}^{\circ} /$ dia) & 23,8 & 21,5 & 22,1 & 22,4 & 1,01 & 0,4575 \\
\hline Número de Períodos de Ócio ( $\mathrm{n}^{\circ} /$ dia) & 19,7 & 23,2 & 21,3 & 22,1 & 1,49 & 0,4151 \\
\hline Duração do Período de Alimentação (min/per.) & 24 & 22,74 & 23,02 & 21,85 & 2,25 & 0,2711 \\
\hline Duração do Período de Ruminação (min/per.) & 23,07 & 24,47 & 23,32 & 23,65 & 2,22 & 0,8699 \\
\hline Duração do Periodo de Ócio (min/per.) & 25,61 & 23,02 & 25,58 & 26,25 & 1,38 & 0,4025 \\
\hline Tempo de Mastigação/bolo, segundos & 54,2 & 55,3 & 51,3 & 55,6 & 2,25 & 0,5200 \\
\hline Número de Bolos Ruminados / dia & 560 & 526 & 515 & 545 & 16,20 & 0,2395 \\
\hline Tempo de Mastigação Total, hs & 15,5 & 15,1 & 14,9 & 14,3 & 0,47 & 0,3281 \\
\hline
\end{tabular}

Não houve diferença na produção de leite corrigida para 3,5\% de gordura $(\mathrm{P}=0,2755)$ entre as dietas experimentais (Tabela 4). Esse resultado é reflexo do mesmo teor de NDT na dieta (Tabela 1), bem como dos semelhantes tempos de consumo de matéria seca (min./ hora) (Tabela 4) e de alimentação (Tabela 3). O farelo de girassol levou os animais a apresentarem menor gasto de tempo $(\mathrm{P}=0,0399)$ com o consumo de FDN em relação aos animais alimentados com ureia, refletindo em menor $(\mathrm{P}=0,0069)$ eficiência alimentar da MS comparado ao tratamento com ureia e de ruminação comparado ao tratamento com mamona desintoxicada. Entretanto, não houve diferença $(\mathrm{P}>0.05)$ com o tempo gasto no consumo de MS, ruminação e mastigação da MS e FDN.

Analisando-se a Tabela 1, poderia ser esperado que a qualidade da fibra dietética ficasse prejudicada com as inclusões dos farelos de girassol e mamona, tendo em vista os maiores teores de FDA desses ingredientes em relação ao farelo de soja. Conforme vários autores ${ }^{(23-28)}$, o tempo despendido com ruminação é altamente correlacionado com o consumo de FDN por bovinos. No entanto, a distribuição da atividade de ruminação é bastante influenciada pela alimentação, já que a ruminação se processa logo após os períodos de alimentação, quando o animal está mais tranquilo ${ }^{(29)}$. Estas teorias são plausíveis desde que a qualidade da fibra consumida pelos bovinos não influencie os fatores produtivos. Quando a digestibilidade da fibra apresenta valores distintos, o resultado pode ser observado no tempo gasto com o consumo deste nutriente. Todavia, possíveis diferenças na qualidade da fibra das dietas experimentais não foram suficientes para alterar o consumo de matéria seca em $\mathrm{min} / \mathrm{kg}$ e consequentemente a produção de leite (Tabela 3). Portanto, apesar de as maiores proporções de FDA nos farelos de girassol e mamona em relação ao farelo de soja, esses ingredientes mostraramse eficientes para o nível de produção de leite observado.

O tempo normal de ruminação em bovinos encontra-se entre 4 a 9 horas/dia, sendo que o consumo diário de alimentos pode ser descrito pelo número de refeições consumidas por dia, pela duração e pela taxa de alimentação, a qual é representada pela velocidade em que cada refeição é feita ${ }^{(30)}$. 
I abela 3. Medias para a produçáo de lette corrıg1da para $3, \supset \%$ de gordura, tempo gasto para consumo, ruminação e mastigação em minutos por kg da matéria seca e de fibra em detergente neutro, efíciência de alimentação e ruminação em gramas por hora, da matéria seca e fibra em detergente neutro de vacas F1 Holandês x zebu alimentadas com diferentes fontes de compostos nitrogenados, coeficientes de variação (CV)

\begin{tabular}{|c|c|c|c|c|c|c|}
\hline \multirow{3}{*}{ Itens } & \multicolumn{4}{|c|}{ Tratamentos } & \multirow[b]{3}{*}{ EPM } & \multirow[b]{3}{*}{$\operatorname{Pr}>\mathrm{Fc}$} \\
\hline & \multicolumn{3}{|c|}{ Farelos } & \multirow[b]{2}{*}{ Ureia } & & \\
\hline & Soja & Girassol & $\begin{array}{c}\text { Mamona S } \\
\text { Desintoxicado }\end{array}$ & & & \\
\hline \multicolumn{7}{|c|}{ Produção de Leite } \\
\hline $\begin{array}{l}\text { Produção de Leite } \\
\text { Corigida }\left(\mathrm{kg} \mathrm{dia}^{-1}\right)\end{array}$ & 20,1 & 20,5 & 19,3 & 20,2 & 0,51 & 0,2755 \\
\hline \multicolumn{7}{|c|}{ Consumo } \\
\hline Matéria Seca $(\mathrm{min} / \mathrm{kg})$ & 28,5 & 29,1 & 31,2 & 30,1 & 0,82 & 0,1277 \\
\hline $\begin{array}{l}\text { Fibra Detergente } \\
\text { Neutro (min/kg) }\end{array}$ & $60,2 \mathrm{ab}$ & $58,7 \mathrm{~b}$ & $60,8 \mathrm{ab}$ & 67,7 a & 2,22 & 0,0399 \\
\hline \multicolumn{7}{|c|}{ Ruminação } \\
\hline Matéria Seca $(\mathrm{min} / \mathrm{kg})$ & 27,9 & 29,1 & 31,2 & 29,2 & 0,99 & 0,1533 \\
\hline $\begin{array}{l}\text { Fibra Detergente } \\
\text { Neutro (min } / \mathrm{kg})\end{array}$ & 59,1 & 58,7 & 60,9 & 65,8 & 2,30 & 0,1398 \\
\hline \multicolumn{7}{|c|}{ Mastigação } \\
\hline Matéria Seca $(\mathrm{min} / \mathrm{kg})$ & $47,6 \mathrm{~b}$ & $50,3 \mathrm{ab}$ & $54,5 \mathrm{a}$ & $47,4 b$ & 2,00 & 0,0630 \\
\hline $\begin{array}{l}\text { Fibra Detergente } \\
\text { Neutro }(\mathrm{min} / \mathrm{kg})\end{array}$ & 100 & 100 & 106 & 106 & 3,76 & 0,4827 \\
\hline \multicolumn{7}{|c|}{ Eficiência de alimentação } \\
\hline Matéria Seca $(\mathrm{g} / \mathrm{h})$ & $2785 \mathrm{ab}$ & $2120 \mathrm{~b}$ & $2899 \mathrm{ab}$ & $3242 \mathrm{a}$ & 204,80 & 0,0069 \\
\hline $\begin{array}{l}\text { Fibra Detergente } \\
\text { Neutro }(g / h)\end{array}$ & 1457 & 1450 & 1382 & 1495 & 72,04 & 0,7326 \\
\hline \multicolumn{7}{|c|}{ Eficiência de ruminação } \\
\hline Matéria Seca $(\mathrm{g} / \mathrm{h})$ & $1960 \mathrm{ab}$ & $1522 \mathrm{~b}$ & $2173 \mathrm{a}$ & $1992 \mathrm{ab}$ & 159,68 & 0,0529 \\
\hline $\begin{array}{l}\text { Fibra Detergente } \\
\text { Neutro }(g / h)\end{array}$ & 1023 & 1047 & 1002 & 921 & 38,51 & 0,1387 \\
\hline
\end{tabular}

Analisando-se os resultados da Tabela 3, verifica-se que os ingredientes farelo de girassol e farelo de mamona desintoxicado, de modo geral, aumentaram o tempo de mastigação da MS em minutos $/ \mathrm{kg}(\mathrm{P}=0,0630)$, o que poderia prejudicar o consumo e influenciar algumas características da fermentação ruminal. De acordo com Antunes et al. ${ }^{(5)}$, a atividade de mastigação tem um importante papel no consumo e digestão de dietas, influenciando a taxa de secreção salivar, solubilizando os nutrientes, quebrando e reduzindo o tamanho das partículas e expondo os nutrientes para a colonização e aumentando a taxa de passagem da digesta. Todavia, apesar de diferenças pontuais em algumas características do comportamento ingestivo, entre as diferentes fontes nitrogenadas, as eficiências de alimentação e ruminação da FDN foram semelhantes, da mesma forma que a produção de leite corrigida para gordura. 


\section{Conclusão}

Algumas características do comportamento ingestivo de vacas F1 Holandês $\times$ Zebu em lactação podem ser alteradas pelo uso de diferentes fontes nitrogenadas; entretanto, não há prejuízo da produção média de $20 \mathrm{~kg}$ de leite corrigida para 3,5\% de gordura/dia. Nestas condições, pode-se substituir totalmente o farelo de soja por fontes alternativas como a ureia e os farelos de girassol e mamona desintoxicada.

\section{Agradecimento}

Ao BNB/Fundeci, pelo auxílio financeiro à pesquisa; À FAPEMIG, CNPq e CAPES pelo auxílio com bolsas.

\section{Referências}

1. Pelizer, L.H.; Pontieri, M.H.; Moraes, I.D. Utilização de rezíduos agro-industriais em processos biotecnológicos como perspectiva de redução do impacto ambiental. Journal of Technology Management \& Innovation, Santiago, 2007; 2(1): 118-127.

2. Lima Júnior, D. M. Braga, A.P., Rangel, A.H.M., Braga, Z.C.A.C., Barreto, H.F.M., Maciel, M.V., Farelo de algodão (Gossipum spp.) extrusado na dieta de ruminantes: consumo e digestibilidade. Acta Veterinaria Brasilica, Mossoró, 2011; 5(1): 68-75.

3. Abdalla, A.L.; Silva Filho, J.C. da; Godoi, A.R.; Carmo, C.A.; Eduardo, J.L.P. Utilização de subprodutos da indústria de biodiesel na alimentação de ruminantes. Revista Brasileira de Zootecnia, Viçosa, 2008; 37(Suplemento Especial): 260-268.

4. Vieira, M.M.M.; Cândido, M.J.D.; Bomfim, M.A.D.; Severino, L.S.; Zapata, J.F.F.; Beserra, L.T.; Meneses, A.J.G.; Fernandes, J.P.B. Características da carcaça e dos componentes não-carcaça em ovinos alimentados com rações à base de farelo de mamona. Revista Brasileira de Saúde e Produção Animal, Salvador, 2010; 5(1): 140-149.

5. Antunes, A.P.S., Rocha Junior, V.R., Ruas J.R.M. Characteristics of the ingestive behavior and milk production of F1 Holstein x Zebu cows fed with diets containing increasing levels of urea. Revista Brasileira de Ciencia Veterinária, 2014; 21(3): 192-198.

6. Pereira, E. S; Pimentel, P.G., Carneiro, M.S.S., Mizubuti, I.Y., Ribeiro, E.L.A., Rocha Junior, J.N., Costa, M.R.G.F. Comportamento ingestivo de vacas em lactação alimentadas com rações a base de torta de girassol. Semina: Ciências Agrárias, Londrina, 2011; 32(3): 1201-1210.

7. Pereira, E. S. Mizubuti, I.Y., Ribeiro, E.L.A., Villarroe, A.B.S., Pimentel, P.G. Consumo, digestibilidade aparente dos nutrientes e comportamento ingestivo de bovinos da raça Holandesa alimentados com dietas contendo feno de capim-tifton 85 com diversos tamanhos de partícula. Revista Brasileira de Zootecnia, Viçosa, 2009; 38: 190-195.

8. National Research Counsil. Nutrient requirements of dairy cattle. 7. ed. Washington: National Academic Press, 2001. 381p.

9. Anandan, S., Kumar, G. K. A.; Ghosh, J.; Ramachandra, K. S.Effect of different physical and chemical treatments on detoxification of ricin in castor cake. Animal Feed Science and Technology, Amsterdan, 2005; 120(1-2): 159-168.

10. Bürger, P. J. Pereira, J.C., Queiroz, A.C., Silva, J.F.C., Valadares Filho3, S.C., Cecon,P.R., Casali, A.D.P. Comportamento ingestivo em bezerros holandeses alimentados com dietas contendo diferentes níveis de concentrado. Revista Brasileira de Zootecnia, Viçosa, 2000; 29(1): 236-242. 
11. Detmann, E.; Souza, M.A.; Valadares Filho, S.C.; Queiroz, A.C.; Berchielli, T.T.; Saliba, E.O.S.; Cabral, L.S.; Pina, D.S.; Ladeira, M.M.; Azevedo, J.A.G. Métodos para Análise de Alimentos. 1 ed. Instituto Nacional de Ciência e Tecnologia de Ciência Animal. 2012. 214p.

12. Van Soest, J. P.; Robertson, J. B.; Lewis, B. A. Methods for dietary fiber, neutral detergent fiber, and nonstarch polysaccharides in relation to animal nutrition. Journal of Animal Science, Champaign, 1991; 74(10): 3583-3597.

13. Detmann, E.; Valadares Filho, S.C. On the estimation of non-fibrous carbohydrates in feeds and diets. Arquivo Brasileiro de Medicina Veterinária e Zootecnia, 2010; 62: 980-984.

14. Sklan, D.; Kaim, M.; Moallem, U.; Folman, Y. Effect of dietary calcium soaps on milk yield, body weight, reproductive hormones, and fertility in first parity and older cows. Journal of Dairy Science, 1994; 77 (6): $1652-1660$.

15. Ferreira, D. F. Sisvar: um computador sistema de análise estatística. Ciência e Agrotecnologia, Lavras, 2011; 35(6): 1039-1042.

16. Detmann E., Valente E.E.L., Batista E.D., Huhtanen P. An evaluation of the performance and efficiency of nitrogen utilization in cattle fed tropical grass pastures with supplementation. Livestock Science. 2014; 162 : 141-153.

17. Farmer C.G., Cochram R.C., Nagaraja T.G., Tigmeyer E.C. Ruminal and host adaptions to changes in frequencies of protein supplementation. Journal of Animal Science, 2004; 82: 895-903.

18. Bispo, S. V. Ferreira, M.A., Véras, A.S.C., Modesto, E.C., Guimarães, A.V., Pessoa, R.A.S. Comportamento ingestivo de vacas em lactação e de ovino alimentados com dietas contendo palma forrageira. Revista Brasileira de Zootecnia, Viçosa, 2010; 39(9): 2024-2031.

19. Miranda, L.F.; Queiroz, A.C.; Valadares Filho, S.C. Paulo Roberto Cecon4, Elzânia Sales Pereira5, José Maurício de Souza Campos3, Rogério de Paula Lanna3, José Rafael Miranda Comportamento ingestivo de novilhas leiteiras alimentadas com dietas à base de cana-de-açúcar. Revista Brasileira de Zootecnia, Viçosa, 1999; 28(3): 614-620.

20. Pinheiro, A. A.; Veloso, C.A., Lima, L.P., Silva, R.R., Silva, F.F., Mendes, F.B.L., Santana Júnior, H.A., Cecato, U., Carvalho,G.G.P. Intervalos entre observações com diferentes escalas de tempo no comportamento ingestivo de vacas leiteiras confinadas. Revista Brasileira de Saúde e Produção Animal, Salvador, 2011; 12(3): 670-679.

21. Jordan, E.; Kenny, D.; Hawkins, M.; Malone, R.; Lovett, D.R.; O'mara, F.P. Effect of refi ned soy oil or whole soybeans on intake, methane output, and performance of young bulls. Journal of Animal Science, 2006; 84: p.2418-2425.

22. Silva, M.M.C. da; Rodrigues, M.T.; Rodrigues, C.A.F.; Branco, R.H.; Leão, M.I.; Magalhães, A.C.M. de; Matos, R. S. Efeito da suplementação de lipídios sobre a digestibilidade e os parâmetros da fermentação ruminal em cabras leiteiras. Revista Brasileira de Zootecnia, Viçosa, 2007; 36(1): 246-256.

23. Souza, C.F.; Rocha Júnior, V.R.; Reis, S.T. dos; Antunes, C.R.; Rigueira, J.P.S.; Sales, E.C.J. de; Soares, C.; Souza, G.R. Casca de banana em dietas para vacas mestiças em lactação. Revista Brasileira de Saúde e Produção Animal, Salvador, 2016; 17(1): 86-100.

24. Barros, R.C.; Rocha Júnior, V.R.; Saraiva, E.P.; Mendes, G.A.; Meneses, G.C.C.; Oliveira, C.R.; Rocha, W.J.B.; Aguiar, A.C.R.; Santos, C.C.R. Comportamento ingestivo de bovinos nelore confinados com diferentes níveis de substituição de silagem de sorgo por cana-de-açúcar ou bagaço de cana amonizado com ureia. Revista Brasileira de Ciência Veterinária, 2011; 18 (1): 6-13.

25. Mendonça, S.S.; Campos, J.M.S.; Valadares Filho, S.C.; Valadares, R.F.D.; Soares, C.A.; Lana, R.P.; Queiroz, A.C.; Assis, A.J.; Pereira, M.L.A. Comportamento ingestivo de vacas leiteiras alimentadas com dietas à base de cana-de-açúcar ou silagem de milho. Revista Brasileira de Zootecnia, Viçosa, 2004; 33 (3): p. 723 - 
728.

26. Pereira, J. C.; Noronha, D.; Cunha, F.V.; Cecon, P.R.; Faria, E.S. Comportamento ingestivo e taxa de passagem de partículas em novilhas leiteiras de diferentes grupos genéticos submetidas a dietas com diferentes níveis de fibra. Revista Brasileira de Zootecnia, Viçosa, 2007 (supl.); 36(6): 2134-2142.

27. Mendes, F.B.L.; Silva, F.F.; Silva, R.R.; Carvalho, G.G.P. de; Cardoso, E.D.; Rocha Neto, A.L.; Oliveira, J.S.; Costa, L.T.; Santana Júnior, H.A.; Pinheiro, A.A. Avaliação do comportamento ingestivo de vacas leiteiras em pastejo de Brachiaria brizantha recebendo diferentes teores de concentrado na dieta. Semina: Ciências Agrárias, Londrina, 2013; 34(6): 2977-2990.

28. Martins, S.C.S.G.; Rocha Júnior, V.R.; Caldeira, L.A.; Barros, I.C.; Silva, G.W.V.; Costa, M.D.; Palma, M.N.N.; Souza, A.S. Comportamento ingestivo de vacas mestiças alimentadas com dietas à base de diferentes volumosos. Revista Brasileira de Ciência Veterinária, Niteroi, 2012; 19(1): 13-20.

29. Polli, V.A.; Restle, J.; Senna, D.B. Aspectos relativos à ruminação de bovinos e bubalinos em regime de confinamento. Revista Brasileira de Zootecnia, Viçosa, 1996; 25(5): 987-993.

30. Carvalho, G. G. P., Pires, A.J.D., Silva, R.R., Ribeiro, L.S.O., Chagas, D.M.T. Comportamento ingestivo de ovinos Santa Inês alimentados com dietas contendo farelo de cacau. Revista Brasileira de Zootecnia, Viçosa, 2008; 37(4): 660-665. 